\title{
Learning from 40 births using the Odon Device for assisted vaginal birth - using case study methodology to explore optimum use
}

\author{
Emily Hotton ${ }^{1}$, Natalie Blencowe ${ }^{2}$, Julia Wade ${ }^{2}$, Nichola Bale ${ }^{1}$, Erik Lenguerrand ${ }^{2}$, Tim \\ Draycott $^{1}$, and Joanna Crofts ${ }^{1}$ \\ ${ }^{1}$ North Bristol NHS Trust \\ ${ }^{2}$ University of Bristol
}

May 21, 2021

\begin{abstract}
Objective To explore optimum use of the Odon Device by establishing the optimal device design, describing the 'usual' steps for use and setting clinical parameters for device use. Design Qualitative case study methodology was embedded in the ASSIST Study - a feasibility study of the Odon Device. Setting Central Delivery Suite, North Bristol NHS Trust, UK. Population Women who required a clinically indicated assisted vaginal birth. Methods Each case was determined by the single use of the Odon Device and could contain data from one or more of the following: formal observation of the Odon assisted birth, an interview with obstetricians, midwives or women involved in an Odon assisted birth. Data collection and analysis ran iteratively and in parallel enabling rapid dissemination of findings. Main outcome measures Determining the optimal steps for device use, recommendations for optimal device design and defining clinical parameters for device use. Results Optimal steps included applying the device during rather than between contractions, having a flexible approach to the application angle and deflating the air cuff sooner than originally proposed. Three design modifications were proposed. The device can be used under local or regional anaesthetic and is successful with all vertex presentations. It is not successful at assisting birth when the vertex is at station spines. Conclusions Case study methodology facilitated rapid insight into optimum device design, device use and key clinical parameter for successful use. This methodology should be considered whenever innovative devices are introduced to clinical trials and settings.
\end{abstract}

Learning from 40 births using the Odon Device for assisted vaginal birth - using case study methodology to explore optimum use

Emily J Hotton ${ }^{1,2}{ }^{*}$, Natalie S Blencowe ${ }^{3,4}$, Julia Wade $^{5}$, Nichola Bale ${ }^{2}$, Erik Lenguerrand ${ }^{1,2}$, Tim J Draycott $^{2}$, Joanna F Crofts ${ }^{2}$

1 Translational Health Sciences, University of Bristol, Bristol, UK

2 Southmead Hospital, North Bristol NHS Trust, Bristol, UK

${ }^{3}$ University Hospitals Bristol NHS Foundation Trust, Bristol, UK

${ }^{4}$ Centre for Surgical Research, Population Health Sciences, University of Bristol, Bristol, UK

${ }^{5}$ Population Health Sciences, University of Bristol, Bristol, UK

\section{* Corresponding Author:}

Women and Children's Academic Research

The Chiltern's 
Maternity Unit

Southmead Hospital

Bristol

United Kingdom

BS10 5NB

Tel: 01174146764

Email: emily.hotton@nhs.net

Running title: Learning from 40 births using the Odon Device

Abstract word count: 245

Word count: 3,496

Objective

To explore optimum use of the Odon Device by establishing the optimal device design, describing the 'usual' steps for use and setting clinical parameters for device use.

\section{Design}

Qualitative case study methodology was embedded in the ASSIST Study - a feasibility study of the Odon Device.

\section{Setting}

Central Delivery Suite, North Bristol NHS Trust, UK.

\section{Population}

Women who required a clinically indicated assisted vaginal birth.

\section{Methods}

Each case was determined by the single use of the Odon Device and could contain data from one or more of the following: formal observation of the Odon assisted birth, an interview with obstetricians, midwives or women involved in an Odon assisted birth. Data collection and analysis ran iteratively and in parallel enabling rapid dissemination of findings.

\section{Main outcome measures}

Determining the optimal steps for device use, recommendations for optimal device design and defining clinical parameters for device use.

\section{Results}

Optimal steps included applying the device during rather than between contractions, having a flexible approach to the application angle and deflating the air cuff sooner than originally proposed. Three design modifications were proposed. The device can be used under local or regional anaesthetic and is successful with all vertex presentations. It is not successful at assisting birth when the vertex is at station spines.

\section{Conclusions}

Case study methodology facilitated rapid insight into optimum device design, device use and key clinical parameter for successful use. This methodology should be considered whenever innovative devices are introduced to clinical trials and settings.

\section{Funding}


Bill \& Melinda Gates Foundation [INV-010180]

\section{Keywords}

Assisted vaginal delivery, qualitative research, translational research

\section{Introduction}

Each year approximately 82,000 women in the UK have an assisted vaginal birth (AVB). In recent years, despite the known advantages of AVB, there has been a rate reduction with a corresponding increase in Caesarean births in the second stage of labour. Despite AVB being an important skill in modern obstetric practice, there have been no new methods for AVB introduced since the 1950s.

Current devices for AVB require a high level of training and skill (with expertise required to define the fetal position) and can be associated with significant maternal and neonatal morbidity if used incorrectly. An innovative device that is easier to use and potentially safer, could contribute to increasing women's access AVB, which in turn would help to reduce the number and associated morbidity of emergency Caesarean sections performed in the second stage. An ideal new device would have a (i) lower rate of maternal complications, (ii) lower rate of neonatal complications, (iii) lower failure rate and (iv) be acceptable to women, obstetricians, midwives and neonatologists.

The Odon Device (Figure 1) is a Class I sterile device. Medical devices are developed to be clinically effective, with safety and performance crucial in ensuring their intended action is achieved without fault. Devices are developed with accompanying Instructions For Use (IFU), which detail the technique and specified parameters for use.

The Odon Device has undergone rigorous pre-clinical, simulation, human factors and Phase 1 first-in human investigation which demonstrated that it appeared to be safe. However, the device had not yet been used in the intended population: women who require an AVB for a clinical indication. Before the device can be introduced into widespread practice the efficacy, expected indications for device use, technique for device use and design of the device need to be examined in the clinical setting.

This study applied qualitative case study methodology to examine in detail how the Odon Device (version 4.1) is used for AVB, and how this use varies with different contextual factors with the aim of (i) establishing the optimal device design, (ii) describing the 'usual' steps for use and (iii) setting clinical parameters for device use. This qualitative research was embedded in the ASSIST Study - a feasibility study of the Odon Device.

\section{Methods}

Forty births were assisted with the Odon Device at North Bristol NHS Trust, UK between October 2018 and January 2019. A case was defined as the single use of the Odon Device and could contain data from one or more of the following: formal observation of the Odon assisted birth, or an interview with obstetricians, midwives or women involved in an Odon assisted birth. Written consent was provided by all participants. Full methods of the ASSIST Study have been published.

Case study methodology enabled the exploration and determination of factors that improve optimal device use through bridging multiple factors relating to the device - technique, design and parameters for use (Figure 2).

\section{Data collection}

Observation of Odon assisted births were undertaken by the lead qualitative researcher and Odon operator through participant observation. All observations including contextual factors and communication were prospectively recorded on a bespoke observation schedule. Detailed analysis of the operative steps performed by the obstetrician during AVBs were recorded enabling a stepwise account of the 'usual steps' to be generated and compared against the IFU. Changes or adaptations to the technique were disseminated to all operators by the lead researcher and through the training programme. 
All women who had the birth of their baby formally observed were invited to participate in an interview at day one postnatal. The operator and midwives present during an Odon assisted birth were invited to take part in an interview conducted within five days of the birth.

Data regarding whether the Odon Device had been successful or unsuccessful was taken from the case report forms.

\section{Triangulation of data}

A narrative report was created for each case, combining all available data. This supported rapid analysis and cross-comparison between cases. Any issues that required clarification from the woman, operator, or midwife were highlighted during the creation of the report allowing them to be discussed during any subsequent interviews for the case in question and for all subsequent uses of the device. This enabled the development of key learning points or corrections to technique to be rapidly disseminated to the obstetricians.

\section{Data analysis}

Data collection and analysis ran iteratively, and in parallel. NVivo 12 (QSR International, Melbourne, Australia) was used to organise data and support analysis. Data were analysed inductively with all data from each case read together to identify and organise codes. Codes were developed and refined reflecting text or expressions that captured significant views in the data. Codes were then grouped to reflect developing themes, with code descriptions and sample quotes assigned. Case summaries were developed and reviewed using constant comparative techniques to assess whether and how to expand or merge themes. Double coding of a proportion of interview transcripts was undertaken by JW. Commonality and variances across cases were discussed between the researchers and used to further shape evolving themes and sampling.

\section{Odon summit}

Following the $36^{\text {th }}$ Odon assisted birth, an interactive summit was held of the clinical research team, design engineers, statisticians and funders to share the learning experiences. The aim was to share learning and to gain consensus regarding the changes to technique, device and clinical parameters for use that had been suggested in the data analysis.

\section{Patient and public involvement}

Patient and public involvement (PPI) was undertaken for all aspects of the ASSIST Study during protocol development. A PPI consultation to establish views on the protocol was held on 22nd March 2018 (pregnant women $(n=8)$, birth partners $(n=4))$. All welcomed the possibility of discussing birth with a researcher during the postnatal period and did not feel that having their birth observed would be a concern. They expected in person observations to occur during intrapartum research but did not feel that videoing would be appropriate.

\section{Funding}

This work was supported, in whole or in part, by the Bill \& Melinda Gates Foundation [INV-010180]

Under the grant conditions of the Foundation, a Creative Commons Attribution 4.0 Generic License has already been assigned to the Author Accepted Manuscript version that might arise from this submission.

\section{Results}

Qualitative data was obtained from 39 of the 40 (97.5\%) single uses of the Odon Device (Table 1).

Device technique

The original IFU was developed prior to this study during the phase 1 clinical and simulation studies and included 22 operative steps. In this IFU, the AVB was divided into six domains according to purpose (Table 2 ). It was hypothesised that the steps may vary between cases, depending on factors such as station and 
position. Qualitative analysis provoked and encouraged operators to discuss cases between themselves, either through telephone calls or via a dedicated end-to-end encrypted messing service.

Principal adaptions to the original IFU included (i) device application during rather than between contractions, (ii) altering the application angle and (iii) deflating the air cuff as soon as any aspect of the blue deflation line became visible.

\section{Device application with a contraction}

The original IFU stated that the Odon Device should be applied between contractions, as is standard practice with other devices for AVB (forceps and ventouse). It became apparent during the first two attempted AVBs that this disimpacted the fetal head out of the pelvis and operators were unable to correctly place the device:

D1: 'Again, I had to use significant pressure to try and get the device over the fetal head. And loads of liquor came down during the application suggesting that there was some degree of disimpaction.'

By the third attempted birth, operators had adapted their technique to include fundal pressure to aid application, which resulted in successful device application and the first successful AVB. The use of fundal pressure, although successful, was not well tolerated by women without a regional anaesthetic:

M3: 'Significant fundal pressure that was used at the time... she was uncomfortable... maybe that will be something up for review.'

Following feedback from qualitative findings, the application technique was adapted again during the eighth birth. This was the first time the Odon Device was applied during a contraction without the use of fundal pressure, resulting in a successful application and birth:

D2: 'I haven't used fundal pressure since delivery number two or three for me, but what has been very successful is putting it on during a contraction. I think.'

\section{Device application angle}

The original IFU stated that the device should be applied 'starting at $45^{\circ}$ below the horizontal'. By the eighth attempted birth it was apparent that this was not the correct angle and operators naturally moved to a more 'horizontal' application:

D2: 'I definitely pushed the device in at a much flatter angle, much more parallel with the bed than I had in the past...'

All operators quickly agreed that the angle required might be dependent on factors such as fetal position and station:

D1: 'So I was kind of like, "Oh, OP, it might be more, you know, it could be difficult because it's an OP..." "

\section{Deflating the air cuff}

The original IFU stated that 'once you see the blue deflation line completely' the air cuff should be deflated. By the third attempted birth it became apparent to the observer that this was too late and actually, the optimum time for air cuff deflation seemed to be when any section of the blue line could be seen:

O5: 'Noticed that it was not the anterior blue deflation line that the operator was looking at the deflate but the posterior deflation line, due to the fact that there is an acute $J$ curve and anterior line not seen. Will need to change this in training.'

This was rapidly disseminated and adopted by all operators.

Device design and performance

Following completion of the ASSIST Study and discussion at the multiprofessional summit, the operators proposed three design modifications for future device adaptations: (i) strengthening the sleeve seal lines, (ii) creating a wider opening between the sleeve handles and (iii) altering the design of the deflation button. 


\section{Sleeve alterations}

One operator noted that the sleeve seal lines tore during traction, with this happening on several occasions:

D4: 'The deliveries have been fine, but the sleeve is not sturdy... That it might actually rip it open, which has happened with me a few times.'

During device inspection, it was noted that all devices had small tears $(<2 \mathrm{~cm})$ in the seal lines of the sleeve, and one had a significant tear $(>7 \mathrm{~cm})$. There was no evidence any of these tears had had any negative effect on the function of the Odon Device. Tearing was thought to have occurred when operators opened the sleeve handles before and between tractions to physically look at the station of the vertex. In contrast to standard device use for AVB, there was little proprioceptive feedback to ascertain the station of the baby, so visual inspection was useful:

O5: '...I got the impression that the operator was unsure as to whether the head had descended so opened the handles to look inside the sleeve. Could see the baby had descended nicely.'

It was recommended that the opening between the two handles was made wider to enable operators to view the progression of the baby's head more easily (Figure S1).

\section{The deflation button}

In six cases it was noticed that the operator accidentally pressed the deflation button. Each time this occurred, the cuff was reinflated immediately. All operators agreed that the design of the deflation button should be altered to reduce the risk of inadvertent activation (Figure S2):

O3: 'Operator accidentally pressed the deflation button 'oh, whoops that was my fault, I'll just re-inflate'.'

\section{Manufacturing fault}

All devices were disinfected and inspected following their use as per protocol. During this inspection, four devices were found to have an ineffective bulb pump (Figure 1) which resulted in inadequate cuff inflation (Table 1). Operators comments during the attempted births reflected this, as the device did not act in the expected manner for them.

D4: 'Yes, there was no grip... It just came out deflated, so it didn't feel right.'

A rapid retrospective review of all used and stored devices was then undertaken to ensure that no other unsuccessful attempts could be attributed to this fault.

Optimal clinical parameters for Odon Device use

The Odon Device was able to successfully assist births in all fetal positions. The midwives were particularly positive about the way the device could deliver a baby in the occipito-posterior position.

M9: 'I think, probably, it could be quite universal as an instrumental device. It didn't seem to matter whether the baby was $O A$ or $O P \ldots$ '.

As experience with the device increased, it became apparent that the device could be used comfortably without a regional anaesthetic and it repeatedly reported to be better tolerated than bladder emptying by urethral catheterisation:

D2: 'She actually found the catheterisation more uncomfortable than putting on the Odon Device with no analgesia at all.'

Conversely it became apparent that for women with fetal station at spines or a more complex presentation (such as brow or nuchal arm) the device was less likely to be successful:

D3: 'On examination, baby's head was asynclitic, deflexed, occiput lateral, at the spines... in the future, I wouldn't apply that, and I would tentatively think about Kiellands but I suspect I wouldn't have been able to apply Kiellands and she'd have had a section anyway.'[unsuccessful Odon-emergency Caesarean section] D1: 
'So, it was direct $O P$ at the spines, and it was almost coming to a brow, I could feel the orbital ridges...I was thinking. "Oh, I'm really not sure that this is going to work.". . I didn't feel that wasn't a failed Odon, that was a baby that was never going to come out vaginally.' [unsuccessful Odon-failed rotational forceps, emergency Caesarean section]

It was observed that the qualitative interviews that enabled the operators to reflect on their most recent births and in some cases led to re-simulation of the birth they had just performed to try and understand why the device may have been unsuccessful.

\section{Odon summit}

All qualitative case study findings relating to device technique, device design and clinical parameters for use were presented at the Odon summit. The clinical research team presented their findings and these were discussed, in-depth, with the manufacturers. Consensus was achieved regarding how the device technique should be modified; however it was agreed that the objective of confirming the IFU was not met, more data was required to achieve this. Clinically important adaptations to device design were agreed upon and the clinical parameters for use were confirmed.

\section{Discussion}

\section{Main findings}

Performing case study research of a novel device on labour ward in an emergency intrapartum setting is feasible and acceptable to those involved. The case studies utilised participant observation as well as indepth interviews with operators, midwives and women to explore the introduction of an innovative device in context and in detail. Experiences and views of all stakeholders were easily obtained and we were able to investigate these in detail. The use of multiple data sources supported a comprehensive evaluation and triangulation of data on the novel device intervention including device design, instructions for use and clinical parameters for use. Operator interviews were found to be of crucial importance when exploring optimum use of the Odon Device and were obtained from 39/40 (97.5\%) cases. Conducting case studies in different contexts (such as different analgesia, different presentations of babies, different operators) enabled commonalities and disparities in technique to be highlighted and thoroughly investigated. Furthermore, case studies enabling rapid understanding of the amendments required to disseminate to the team such as applying the device during a contraction. Principal technique adaptations were centred on device application and deflation of the air cuff. Device modifications were recommended for useability rather than to transform the functionality of the device. Optimal parameters for device use were proposed and focussed primarily on the station of the baby.

Case study methodology enabled real-time evaluation of device introduction, including technique for device use and the operator "learning curve", the phrase that is commonly used to describe the clinicians' process of gaining knowledge and improved skills in performing a procedure. Despite having no universal definition "learning curve" is accepted to reflect the number of and/or time taken to independently perform a procedure with a satisfactory outcome. It is widely appreciated that there is a substantial operator learning curve when introduced to a novel device; however, this curve can vary in how steep it is. An operator's background expertise or experience may also affect the results of a medical device trial. Variety in operator experience will invariably lead to different levels of performance when using a novel device, with the success of novel device use potentially disproportionally impacted by lack of experience. Most of the research on operator learning curve for novel devices is published when the technique is stable, not during Stage 2 trials where understanding of technique may still be developing. Operators were initially trying to use the Odon Device like other devices (forceps and ventouse) but realised early on that they had to be open-minded to learning a completely new technique (such as applying the device with a contraction). Case study methodology encouraged operators to reflect, critique and appraise their use of the device for each birth, resulting in enhanced and enriched communication between operators regarding their experiences through conversations and a dedicated operator messaging group. In future, data from encrypted social media platforms could be incorporated into the qualitative data for analysis. 


\section{Strengths and limitations}

This research aimed to create a holistic approach to understanding optimum Odon Device use through adopting case study research. An AVB is a complex intervention and this makes studying the use of the device challenging. A complex intervention can be defined as having a number of interacting components which can act independently or interdependently to influence outcomes. Qualitative case study methodology uses multiple data sources from multiple cases to study phenomena: enabling the researcher to assess differences and similarities through the methodology of systematic cross comparison. Recently, qualitative case study methodology has been used to explore technique in surgical procedures however, there are no published examples of case study methodology being used to investigate any novel devices. Triangulation of case study findings from observations and interviews sped up the process of device investigation by being able to promptly confirm modifications for optimum device use. Operator interviews were particularly beneficial in optimising techniques for device use. Combined with rapid analysis, findings could be disseminated rapidly to operators. By using this methodology and incorporating data from all stakeholders and observations we were able to gain a balanced and comprehensive assessment of the use of the device. Participant observation was selected, enabling the researcher to play an active role in the setting if needed and become immersed in the environment. This allowed exploration of reality and contextual factors in real time. However, participant observation may be influenced by the interpretation of the individual researcher. It could be argued that participant observation is actually good practice as reflects standard practice of team working and learning. Interviews with operators were undertaken for all but one case. These were of crucial importance in understanding optimal device use. Little new data transpired from observation and women's interviews after eight cases, so data collection focused on operator interview going forward. The flexibility of case study methodology allowed data collection to respond to initial findings and to focus on the most informative mode of data collection.

Case studies within the ASSIST Study were finite. Observations were undertaken where possible, however due to the unpredictable nature of AVBs it was not possible to attend all assisted births. Indeed, none of the more complex attempted AVBs performed in the operating theatre were observed.

\section{Interpretation}

The clinical research team were able to propose evidence-based modifications to the device design and provide clarity on recommendations for clinical parameters for use. The objective of confirming a finalised IFU was not met. For some operative steps a consensus was easily acquired as to the recommended course of action. However for others more data and experience are required. Case studies provided a comprehensive, contextualised data to support rapid evaluation which significantly contributed to the understanding the Odon Device in clinical practice.

Two further Odon Device feasibility studies, which are currently recruiting in the UK and France, aim to address the unanswered aspects of optimal device use, specifically the technique.

\section{Conclusion}

Case study methodology facilitated understanding of optimal technique, design and clinical parameters for use of the Odon Device. Systematic triangulation of data from varying data sources provided a comprehensive, contextual overview of device use and rapid understanding of amendments required. It also facilitated enhanced operator communication and consensus building, which was key in understanding and developing the iterative adaptations to the technique, device and parameters for device use. This methodology should be considered whenever innovative devices are introduced to clinical trials and settings. It allows for rapid assessment of device use and can support timely iterative adaptions to ensure there are minimal delays between device use in research and adoption in clinical practice.

\section{Acknowledgements}

The authors would like to thank all the women who agreed to take part in this research and all the maternity staff who enabled to safe completion of the ASSIST Study. 


\section{Disclosure of interests}

EL is a member of University of Bristol (UoB) and part of his salary is paid by PROMPT Maternity Foundation (PMF) to UoB; PMF has received funding from a Saving Lives at Birth award via a subcontract from Becton, Dickinson and Company (BD) to conduct preclinical simulation studies of the Odon Device, these funds have been used towards the salary of TJD and JFC when undertaking the simulations studies. All other authors report no competing interests.

\section{Contribution to Authorship}

EJH, NSB and JW developed the concept for the qualitative research. EJH performed all data collection and analysis with co-coding performed by JW. EJH wrote the initial draft of the manuscript. All authors reviewed and approved the final manuscript.

\section{Ethical approval}

The research was approved by South Central-Berkshire REC, UK on $3^{\text {rd }}$ September 2018 (18/SC/0344), the MHRA on $9^{\text {th }}$ August 2018 and the HRA on $3^{\text {rd }}$ September 2018.

Table/figure caption list

Table 1 Summary of 40 cases investigating the Odon Device with adaptations made to device technique

Table 2 Original components of application of the Odon Device for an assisted vaginal birth

Figure 1 Diagram of the Odon Device

Figure 2 How case study methodology may be able to determine optimal device use

Supplementary figure 1 (S1) Modifications to the sleeve opening - version 4.1 (left) and version 4.2 (right)

Supplementary figure 2 (S2) Modifications to the deflation button - version 4.1 (left) and version 4.2 (right)

\section{References}

Table 1 Summary of 40 cases investigating the Odon Device with adaptations made to device technique

\begin{tabular}{|c|c|c|c|c|c|c|}
\hline $\begin{array}{l}\text { Case study } \\
\text { no. }\end{array}$ & $\begin{array}{l}\text { Successful } \\
\text { (S) } \\
\text { Unsuccessful } \\
\text { (U) AVB } \\
\text { with Odon } \\
\text { and mode of } \\
\text { birth }\end{array}$ & Observation & $\begin{array}{l}\text { Interviews } \\
\text { Women } \\
\text { Operator } \\
\text { Midwife }\end{array}$ & $\begin{array}{l}\text { Interviews } \\
\text { Women } \\
\text { Operator } \\
\text { Midwife }\end{array}$ & $\begin{array}{l}\text { Interviews } \\
\text { Women } \\
\text { Operator } \\
\text { Midwife }\end{array}$ & Device issues \\
\hline 1 & $\mathrm{U}-$ Forceps & O1 & W1 & D1 & M1 & \\
\hline 2 & $\mathrm{U}-$ Forceps & & & D2 & M2 & \\
\hline $\begin{array}{l}\text { Fundal } \\
\text { pressure } \\
\text { during } \\
\text { device } \\
\text { application } \\
\text { introduced } \\
3\end{array}$ & $\begin{array}{l}\text { Fundal } \\
\text { pressure } \\
\text { during } \\
\text { device } \\
\text { application } \\
\text { introduced } \\
\mathrm{S} \text { - Odon }\end{array}$ & $\begin{array}{l}\text { Fundal } \\
\text { pressure } \\
\text { during } \\
\text { device } \\
\text { application } \\
\text { introduced }\end{array}$ & $\begin{array}{l}\text { Fundal } \\
\text { pressure } \\
\text { during } \\
\text { device } \\
\text { application } \\
\text { introduced }\end{array}$ & $\begin{array}{l}\text { Fundal } \\
\text { pressure } \\
\text { during } \\
\text { device } \\
\text { application } \\
\text { introduced } \\
\text { D2 }\end{array}$ & $\begin{array}{l}\text { Fundal } \\
\text { pressure } \\
\text { during } \\
\text { device } \\
\text { application } \\
\text { introduced } \\
\text { M2 M3 }\end{array}$ & $\begin{array}{l}\text { Fundal } \\
\text { pressure } \\
\text { during } \\
\text { device } \\
\text { application } \\
\text { introduced }\end{array}$ \\
\hline
\end{tabular}




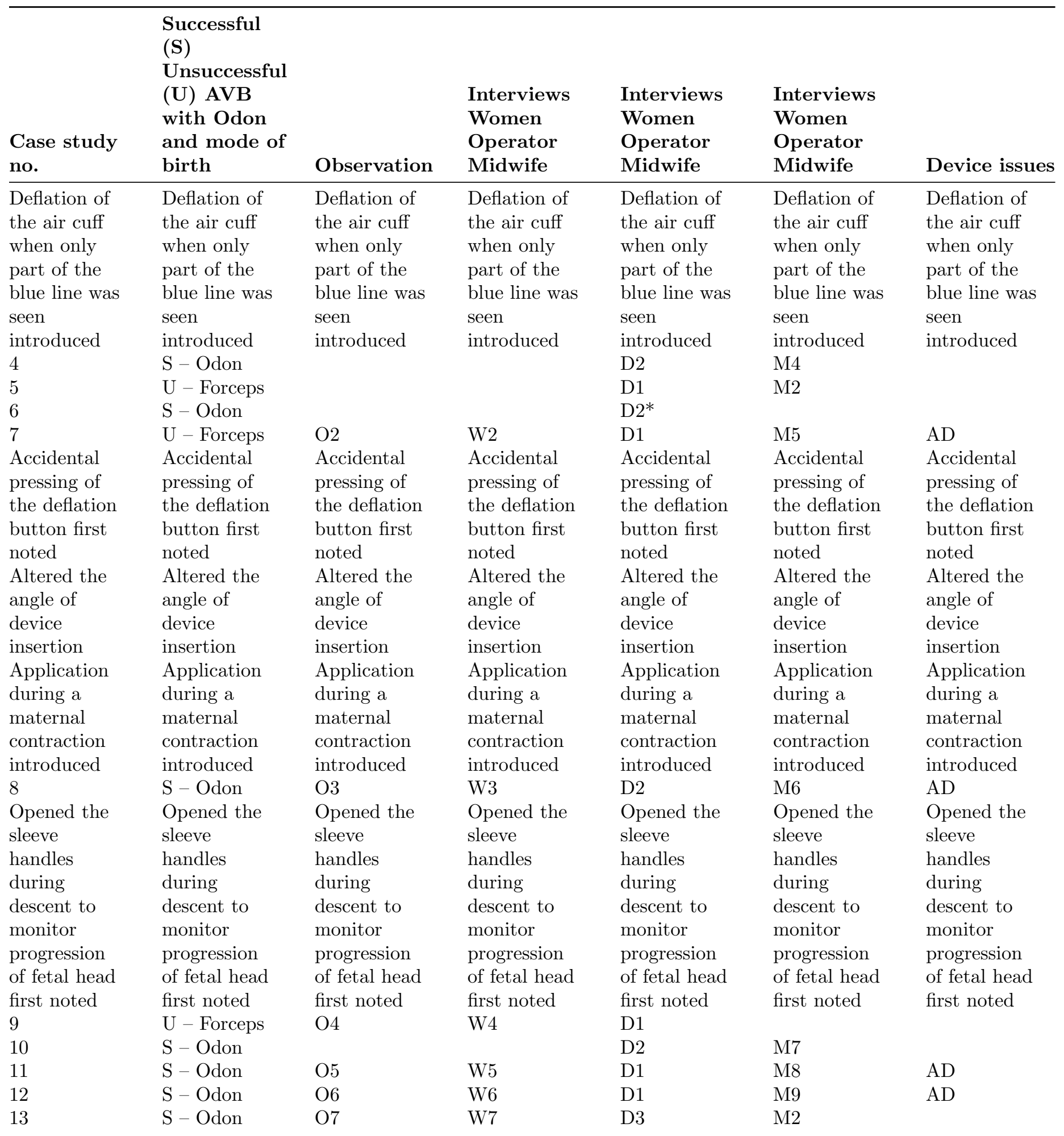




\begin{tabular}{|c|c|c|c|c|c|c|}
\hline $\begin{array}{l}\text { Case study } \\
\text { no. }\end{array}$ & $\begin{array}{l}\text { Successful } \\
\text { (S) } \\
\text { Unsuccessful } \\
\text { (U) AVB } \\
\text { with Odon } \\
\text { and mode of } \\
\text { birth }\end{array}$ & Observation & $\begin{array}{l}\text { Interviews } \\
\text { Women } \\
\text { Operator } \\
\text { Midwife }\end{array}$ & $\begin{array}{l}\text { Interviews } \\
\text { Women } \\
\text { Operator } \\
\text { Midwife }\end{array}$ & $\begin{array}{l}\text { Interviews } \\
\text { Women } \\
\text { Operator } \\
\text { Midwife }\end{array}$ & Device issues \\
\hline 14 & $\begin{array}{l}\mathrm{U} \text { - Failed } \\
\text { rotational } \\
\text { forceps, } \\
\text { emergency } \\
\text { Caesarean } \\
\text { section }\end{array}$ & & & D1 & M7 & $\mathrm{AD}$ \\
\hline 15 & $\mathrm{U}$ - Forceps & & & D2 & M4 & \\
\hline 16 & $\mathrm{U}-$ Forceps & O8 & W8 & D2 & M10 & IBP \\
\hline 17 & S - Odon & & & D1 & & \\
\hline 18 & $\mathrm{~S}-$ Odon & & & D3 & M11 & \\
\hline 19 & $\mathrm{~S}-$ Odon & & & D4 & & SST \\
\hline 20 & $\begin{array}{l}\text { U - } \\
\text { Rotational } \\
\text { forceps }\end{array}$ & & & D4 & & IBP \\
\hline 21 & $\begin{array}{l}\mathrm{U}- \\
\text { emergency } \\
\text { Caesarean } \\
\text { section }\end{array}$ & & & D3 & M6 & \\
\hline 22 & $\mathrm{U}$ - Forceps & & & D4 & & \\
\hline 23 & $\mathrm{U}$ - Forceps & & & D1 & M6 & IBP \\
\hline 24 & S - Odon & & & D1 & & \\
\hline 25 & $\mathrm{U}$ - Forceps & & & D4 & & \\
\hline 26 & $\mathrm{U}$ - Forceps & & & D4 & & \\
\hline 27 & S - Odon & & & D1 & & $\mathrm{AD}$ \\
\hline 28 & $\mathrm{U}$ - Forceps & & & D1 & & \\
\hline 29 & S - Odon & & & D5 & & \\
\hline 30 & $\mathrm{U}$ - Forceps & & & D1 & & \\
\hline 31 & $\mathrm{U}$ - Forceps & & & $\mathrm{D} 4$ & & IBP \\
\hline 32 & $\mathrm{U}$ - Forceps & & & D1 & & \\
\hline 33 & $\mathrm{~S}-$ Odon & & & D5 & & \\
\hline 34 & $\mathrm{~S}-$ Odon & & & D2 & & \\
\hline 35 & $\mathrm{~S}-$ Odon & & & D2 & & \\
\hline 36 & $\mathrm{U}$ - Forceps & & & $\mathrm{D} 4$ & & \\
\hline $\begin{array}{l}\text { Odon } \\
\text { summit held } \\
37 \\
38\end{array}$ & $\begin{array}{l}\text { Odon } \\
\text { summit held } \\
\mathrm{U}-\text { Forceps } \\
\mathrm{S}-\text { Odon }\end{array}$ & $\begin{array}{l}\text { Odon } \\
\text { summit held }\end{array}$ & $\begin{array}{l}\text { Odon } \\
\text { summit held }\end{array}$ & $\begin{array}{l}\text { Odon } \\
\text { summit held } \\
\text { D1 } \\
\text { D4 }\end{array}$ & $\begin{array}{l}\text { Odon } \\
\text { summit held }\end{array}$ & $\begin{array}{l}\text { Odon } \\
\text { summit held }\end{array}$ \\
\hline 39 & $\mathrm{~S}-$ Odon & & & D4 & M6 & \\
\hline 40 & $\mathrm{U}$ - Forceps & & & D3 & & \\
\hline
\end{tabular}

*Qualitative interview from Obstetrician not obtained for this birth $\mathrm{O}=$ observation, $\mathrm{W}=$ woman, $\mathrm{D}=$ Obstetrician, $\mathrm{M}=$ Midwife 
$\mathrm{AD}=$ accidental deflation, $\mathrm{IBP}=$ ineffective bulb pump, $\mathrm{SST}=$ significant sleeve tear

Bold italic steps $=$ key stages in the study that impacted on technique

Table 2 Original components of application of the Odon Device for an assisted vaginal birth

\begin{tabular}{|c|c|}
\hline Component & Steps within component \\
\hline Preparation & $\begin{array}{l}\text { Checking clinical pre-requisites for AVB } \\
\text { Lubricating the device }\end{array}$ \\
\hline Device application & $\begin{array}{l}\text { Removing the fastening band Applying the device } \\
\text { onto a fetal head }\end{array}$ \\
\hline Cuff inflation & $\begin{array}{l}\text { Ensuring the cuff is fully inflated in the correct } \\
\text { position on the fetal head }\end{array}$ \\
\hline Applicator removal & Removing the applicator from the fetal head \\
\hline Traction & $\begin{array}{l}\text { Following the J-shape curve of the pelvis applying } \\
\text { traction with contractions }\end{array}$ \\
\hline Removal of device & Deflating the air cuff as the fetal head is crowning \\
\hline
\end{tabular}

\section{Hosted file}

Figure_1.docx available at https://authorea.com/users/371263/articles/522893-learning-from40-births-using-the-odon-device-for-assisted-vaginal-birth-using-case-study-methodologyto-explore-optimum-use

\section{Hosted file}

Figure_2_.docx available at https://authorea.com/users/371263/articles/522893-learning-from40-births-using-the-odon-device-for-assisted-vaginal-birth-using-case-study-methodologyto-explore-optimum-use 